\title{
Metabolic Syndrome Is Associated With Rapid Estimated Glomerular Filtration Rate Decline In A Chinese Community-Based Population
}

This article was published in the following Dove Press journal:

Diabetes, Metabolic Syndrome and Obesity: Targets and Therapy

\section{Zhongli Wu \\ Yimeng Jiang \\ Jia Jia \\ Danmei He \\ Pengfei Sun \\ Jianping $\mathrm{Li}$ i \\ Yong Huo \\ Fangfang Fan (iD) \\ Yan Zhang}

Department of Cardiology, Peking University First Hospital, Beijing, People's Republic of China
Correspondence: Fangfang Fan; Yan Zhang Department of Cardiology, Peking University First Hospital, Beijing 100034 , People's Republic of China Tel +86 I0 $83575262 ;$ +86 I0 83575728

Fax +86 106655 I383

Email fang9020@126.com;

drzhyl108@163.com
Purpose: This study aimed to determine the relationship between the metabolic syndrome (MetS) and rapid estimated glomerular filtration rate (eGFR) decline in a Chinese community-based population.

Patients and methods: A total of 3108 participants were recruited between December 2011 and July 2014 from an observational study cohort designed for the study of atherosclerotic diseases in Beijing, China. The outcome was a rapid eGFR decline. Subgroup and interaction analyses were performed with respect to a number of covariates.

Results: Over a median follow-up period of 2.34 (IQR: 2.29-2.41) years, the overall incidence of rapid eGFR decline was $7.24 \%$. We found that the MetS was significantly associated with the risk of rapid eGFR decline (odds ratio $[\mathrm{OR}]=1.69,95 \%$ confidence interval $[\mathrm{CI}]: 1.28-2.23, p<0.001)$ in a model adjusted for age, sex, and eGFR, and this relationship remained significant after adjustment for smoking, drinking, and lowdensity lipoprotein-cholesterol ( $\mathrm{OR}=1.78,95 \% \mathrm{CI}: 1.34-2.35, p<0.001)$. Waist circumference $(\mathrm{OR}=1.38,95 \% \mathrm{CI}: 1.04-1.83, p=0.027)$, triglycerides $(\mathrm{OR}=1.40,95 \% \mathrm{CI}$ : $1.05-1.86, p=0.022)$, blood pressure (OR=2.05, 95\% CI: $1.49-2.82, p<0.001)$, and fasting plasma glucose $(\mathrm{OR}=2.12,95 \% \mathrm{CI}: 1.57-2.85, p<0.001)$, but not high-density lipoprotein-cholesterol $(\mathrm{OR}=1.26,95 \% \mathrm{CI}$ : $0.94-1.69, p=0.117)$, were positively associated with the risk of rapid eGFR decline. Similarly, an increase in the number of MetS components present was associated with an increase in the risk of rapid eGFR decline. Furthermore, this association was modified by smoking status $(\mathrm{OR}=3.78,95 \%$ CI: $1.68-8.49, p$-interaction $=0.030)$.

Conclusion: The MetS independently predicted rapid eGFR decline in a Chinese community-based cohort recruited for the study of atherosclerosis. The relationship between the MetS and the risk of rapid eGFR decline was modified by smoking status. Keywords: metabolic abnormalities, estimated glomerular filtration rate, kidney function, atherosclerosis

\section{Plain Language Summary} Why Was The Study Done?

- Metabolic syndrome (MetS) has been considered as a serious public health problem globally. MetS shares many risk factors with chronic kidney disease (CKD).

- Few data exist regarding the predicting value of MetS for rapid eGFR decline in Chinese community-based populations. 


\section{What Did The Researchers Do And Find?}

- In this Chinese community-based cohort, MetS was significantly associated with the risk of rapid eGFR decline.

- Of individual components of MetS, waist circumference, triglycerides, blood pressure, and fasting plasma glucose except HDL-C were all associated with the risk of rapid eGFR decline. High fasting plasma glucose and blood pressure were the two most important risk factors.

- The risk of rapid eGFR decline increased with an increase in the number of MetS components.

- The MetS-rapid eGFR decline association was modified by the status of current smoking.

\section{What Do These Results Mean?}

- The prospective intervention and treatment of MetS components may help slowdown the decline in kidney function and confer potential benefits.

\section{Introduction}

The metabolic syndrome (MetS) is a cluster of risk factors for cardiovascular disease, consisting of abdominal obesity, dyslipidemia (high triglyceride and low high-density lipoprotein-cholesterol [HDL-C] concentrations), high blood pressure (BP), and high fasting glucose or diabetes and is considered to be a serious public health problem globally. In US adults, the prevalence of the MetS was $18.3 \%$ among those aged 20-39 years and $46.7 \%$ among those aged $\geq 60$ years. $^{1}$ In mainland China, the prevalence of the MetS has been reported to be $24.5 \%$ in people aged $\geq 15$ years and to increase with age. ${ }^{2}$

Chronic kidney disease (CKD), another risk factor for cardiovascular disease, is an important public health problem and is highly prevalent $(10.8 \%$, 95\% CI: $10.2-$ $11.3 \%$ ) in China. ${ }^{6}$ The MetS shares many risk factors with CKD. Indeed, previous studies have shown that the MetS is a risk factor for type 2 diabetes mellitus, cardiovascular disease, and all-cause mortality. ${ }^{3-5,24}$ Notably, there is a significant association between the MetS and CKD. ${ }^{7,10,17-19}$ Patients with the MetS have a 2.5-fold higher risk of CKD. ${ }^{8}$ In addition, a cohort study conducted in Japan suggested that the MetS is associated with the progression of $\mathrm{CKD},{ }^{11}$ and a 10 -year prospective cohort study showed that individuals with the MetS have a higher risk of rapid estimated glomerular filtration rate (eGFR) decline than those without (OR: 1.20, 95\% CI: 1.04-1.39). ${ }^{12}$ However, the relationship between the MetS and rapid eGFR decline, especially in Chinese people who do not have CKD or cardiovascular disease, is not well understood. Given that prospective cohort studies have not been conducted to address this question in mainland China, we aimed to determine the relationship between the MetS and rapid eGFR decline in a Chinese population.

\section{Materials And Methods Study Population}

Participants were recruited from among the participants in an observational cohort survey regarding atherosclerosis diseases that was conducted between December 2011 and July 2014 in Beijing, China. The study procedures have been documented elsewhere. ${ }^{21}$ Initially, 5962 participants aged $\geq 40$ years who had undergone a baseline survey were invited to participate in a follow-up examination in 2014, of whom 3823 $(64.1 \%)$ responded on site. From these, participants who were missing blood creatinine values at revisit were excluded $(n=14)$. Then, participants with coronary heart disease, stroke, peripheral arterial disease $(\mathrm{ABI}<0.9)$, or $\mathrm{CKD}$, defined by an eGFR of $<60 \mathrm{~mL} /$ $\min / 1.73 \mathrm{~m}^{2}$, at baseline were excluded $(\mathrm{n}=701)$. Thus, 3108 participants were eligible for the present study.

This study was approved by the Ethics Committee of Peking University First Hospital. Written informed consent was obtained from all the participants before data collection.

\section{Measurements Made}

As described previously, ${ }^{21}$ baseline data were collected by trained researchers according to standard operating procedures. All the participants were interviewed using a standardized questionnaire that included questions about demography, health behavior, and medical history. Current smoking was defined as smoking at least one cigarette per day for at least 6 months and current drinking was defined as drinking alcohol at least once per week for at least 6 months.

The participants underwent a series of anthropometric and other measurements. Body mass index (BMI) was calculated as weight $(\mathrm{kg})$ divided by height $(\mathrm{m})$ squared. The participants were required to rest for 5 mins before seated brachial blood pressure measurements were performed. Systolic blood pressure (SBP) and diastolic blood pressure (DBP) were measured in the right arm using a calibrated Omron HEM-7117 electronic sphygmomanometer. Triplicate measurements were 
performed with 1 min between successive readings, and the mean value was calculated and used in the analysis.

Venous blood samples were obtained from the forearm of participants that had fasted overnight. Serum or plasma samples were separated within 30 mins and stored at $-80^{\circ}$ C. Fasting blood glucose (FBG), 2-hr glucose concentration in the standard $75-\mathrm{g}$ oral glucose tolerance test (OGTT), HDL-C, low-density lipoprotein (LDL)-cholesterol, and triglyceride (TG) concentrations were measured using a Roche C8000 Automatic Analyzer. Serum creatinine concentration at baseline and follow-up were analyzed using the enzymatic method and Jaffe's kinetic method, respectively, as described previously. ${ }^{21}$ The values obtained were transformed using the enzymatic equation and standardized to one core laboratory values. EGFR was calculated using the equation published by the Chronic Kidney Disease Epidemiology Collaboration (CKD-EPI). ${ }^{22}$

\section{Definition Of The Metabolic Syndrome}

The criteria for the $\mathrm{MetS}^{25}$ were those developed by the National Heart, Lung and Blood Institute/American Heart Association and International Diabetes Federation. We defined the MetS as the presence of any three of the following five components: (1) central adiposity, based on ethnicity-specific waist circumference cut-offs ( $\geq 90 \mathrm{~cm}$ in men or $\geq 80 \mathrm{~cm}$ in women); (2) triglyceride (TG) $\geq 1.7 \mathrm{mmol} / \mathrm{L}$ or the use of antihyperlipidemic therapy; (3) HDL cholesterol < $1.0 \mathrm{mmol} / \mathrm{L}$ in men or $<1.3 \mathrm{mmol} / \mathrm{L}$ in women or the use of antihyperlipidemic therapy; (4) $\mathrm{SBP} \geq 130 \mathrm{~mm} \mathrm{Hg}$ or DBP $\geq$ $85 \mathrm{~mm} \mathrm{Hg}$ or the use of antihypertensive medication; (5) $\mathrm{FBG} \geq 5.6 \mathrm{mmol} / \mathrm{L}$ or a diagnosis of diabetes.

\section{Outcomes}

The study outcome was rapid eGFR decline, which was defined as a decline in eGFR of $>3 \mathrm{~mL} / \mathrm{min} / 1.73 \mathrm{~m}^{2} /$ year. $^{23}$

\section{Statistical Analysis}

Hypertension was self-reported, or defined by an SBP $\geq 140 \mathrm{mmHg}$ or a DBP $\geq 90 \mathrm{mmHg}$, or the use of antihypertensive therapy. Diabetes mellitus was self-reported, or defined by the presence of an FBG of $\geq 7.0 \mathrm{mmol} / \mathrm{L}$ or a 2 $\mathrm{hr}$ OGTT value of $\geq 11.1 \mathrm{mmol} / \mathrm{L}$, or the use of antidiabetic therapy. Dyslipidemia was self-reported, or defined by a TG concentration $\geq 1.70 \mathrm{mmol} / \mathrm{L}$, a total cholesterol (TC) concentration $\geq 5.18 \mathrm{mmol} / \mathrm{L}$, an LDL-C concentration $>3.37 \mathrm{mmol} / \mathrm{L}$, an HDL-C concentration $<1.04 \mathrm{mmol} / \mathrm{L}$, or the use of antihyperlipidemic therapy.
Data are presented as the mean \pm standard deviation (SD) or as numbers and percentages for continuous or categorical variables, respectively. The MetS and rapid eGFR decline were analyzed as dichotomous variables, and BMI was analyzed as both a continuous and a categorical variable. The characteristics of all the participants and the differences among the participants, according to the presence or absence of the MetS were compared using Student's $t$-test for normally distributed continuous variables or Pearson's $\chi^{2}$ test for categorical variables. Univariate and multivariate logistic regression models were used to characterize the relationship between the MetS and rapid eGFR decline. The covariates adjusted for in the multivariate analysis were sex, age, baseline eGFR, LDL-C concentration, current smoking, and current drinking. Subgroup and interaction analyses were performed with regard to all these covariates. $P<0.05$ (two-sided) was considered to represent statistical significance. Data analysis was performed using Empower(R) (www.empowerstats.com, $\mathrm{X} \& \mathrm{Y}$ solutions, Inc. Boston MA) and R (http://www.R-project.org).

\section{Results}

Table 1 shows the baseline characteristics of the participants, both overall and categorized according to the presence or absence of the MetS. Thirty-five percent of the participants were men, and they had a mean age of $55.78 \pm 8.09$ years and a mean BMI of $25.95 \pm 3.34 \mathrm{~kg} /$ $\mathrm{m}^{2}$. Forty-four-point-eight percent had hypertension, $14.90 \%$ had diabetes mellitus, and $41.57 \%$ had the MetS. Their mean baseline eGFR was $101.89 \pm 10.25$ $\mathrm{mL} / \mathrm{min} / 1.73 \mathrm{~m}^{2}$. Participants with the MetS, of whom $66.60 \%$ were women, were older, had a higher BMI, had higher prevalence of hypertension, diabetes mellitus, and renal function decline, but had a lower eGFR at baseline. Furthermore, participants with the MetS had a significantly higher waist circumference, SBP and DBP, higher TG, TC, and LDL-C concentrations, and a lower HDL-C concentration.

Over a median follow-up period of 2.34 years (25th75th centile: 2.29-2.41), the incidence of rapid eGFR decline was $7.24 \%$, and $121(9.37 \%)$ of the participants with the MetS and 104 (5.73\%) without demonstrated a rapid decline in eGFR.

Table 2 shows the effects of the MetS on the incidence of rapid eGFR decline, determined using multivariate regression analysis. A positive association between the MetS and rapid eGFR decline was obtained after 
Table I Baseline Characteristics Of The Participants

\begin{tabular}{|c|c|c|c|c|}
\hline Variables & Overall & Without MetS & With MetS & $P$-value \\
\hline $\mathrm{N}, \mathrm{n}(\%)$ & 3108 & $1816(58.43)$ & $1292(41.57)$ & \\
\hline Age, years & $55.78 \pm 8.09$ & $54.66 \pm 7.84$ & $57.36 \pm 8.17$ & $<0.001$ \\
\hline Male, n (\%) & $1087(35.00)$ & $656(36.10)$ & $431(33.40)$ & 0.111 \\
\hline Waist circumference, $\mathrm{cm}$ & $82.47 \pm 8.45$ & $79.32 \pm 7.74$ & $86.91 \pm 7.35$ & $<0.001$ \\
\hline BMI, $\mathrm{kg} / \mathrm{m}^{2}$ & $25.95 \pm 3.34$ & $24.78 \pm 2.99$ & $27.61 \pm 3.08$ & $<0.001$ \\
\hline $\mathrm{SBPm}, \mathrm{mmHg}$ & $132.62 \pm 16.18$ & $128.15 \pm 15.31$ & $138.90 \pm 15.26$ & $<0.001$ \\
\hline $\mathrm{DBPm}, \mathrm{mmHg}$ & $75.32 \pm 9.61$ & $73.55 \pm 9.05$ & $77.80 \pm 9.82$ & $<0.001$ \\
\hline Triglycerides ${ }^{\mathrm{a}}, \mathrm{mmol} / \mathrm{L}$ & $1.29(0.91-1.86)$ & $1.06(0.79-\mid .4 I)$ & $1.81(1.29-2.45)$ & $<0.001$ \\
\hline Total cholesterol, $\mathrm{mmol} / \mathrm{L}$ & $5.35 \pm 0.99$ & $5.27 \pm 0.92$ & $5.44 \pm 1.07$ & $<0.001$ \\
\hline $\mathrm{HDL}-\mathrm{C}, \mathrm{mmol} / \mathrm{L}$ & $1.45 \pm 0.38$ & $1.57 \pm 0.37$ & $1.27 \pm 0.32$ & $<0.001$ \\
\hline LDL-C, $\mathrm{mmol} / \mathrm{L}$ & $3.26 \pm 0.83$ & $3.19 \pm 0.78$ & $3.37 \pm 0.89$ & $<0.001$ \\
\hline eGFR, $\mathrm{mL} / \mathrm{min}$ per $1.73 \mathrm{~m}^{2}$ & $101.89 \pm 10.25$ & $102.77 \pm 10.00$ & $100.66 \pm 10.48$ & $<0.001$ \\
\hline Current smoking, n (\%) & $594(19.10)$ & $357(19.70)$ & $237(18.30)$ & 0.358 \\
\hline Current drinking, n (\%) & $732(23.60)$ & $460(25.30)$ & $272(21.10)$ & 0.006 \\
\hline Hypertension, n (\%) & |39| (44.80) & $553(30.50)$ & $838(64.90)$ & $<0.001$ \\
\hline Diabetes mellitus, $\mathrm{n}(\%)$ & $464(14.90)$ & $140(7.70)$ & $324(25.10)$ & $<0.001$ \\
\hline
\end{tabular}

Notes: Data are presented as mean \pm SD or median (IQR) for continuous variables and percentage for dichotomous variables. ${ }^{\mathrm{a}}$ Median (interquartile range).

Abbreviations: MetS, metabolic syndrome; BMI, body mass index; eGFR, estimated glomerular filtration rate; SBPm, mean systolic blood pressure; DBPm, mean diastolic blood pressure; HDL-C, high-density lipoprotein-cholesterol; LDL-C, low-density lipoprotein-cholesterol.

adjustment for age, sex, and eGFR, with an odds ratio (OR) (95\% confidence interval [CI]) of 1.69 (1.28, 2.23), and this relationship remained statistically significant after adjustment for other covariates, with an OR (95\% CI) of $1.78(1.34,2.35)$. Of the individual components of the MetS, waist circumference, triglycerides, blood pressure, and fasting plasma glucose were all associated with the risk of rapid eGFR decline, with ORs (95\% CI) of 1.38 (1.04, 1.83), 1.40 (1.05, 1.86), 2.05 (1.49, 2.82), 2.12 $(1.57,2.85)$, and $1.26(0.94,1.69)$, respectively, but HDL-C was not. Among these five components, high fasting plasma glucose and blood pressure carried the greatest risks of rapid eGFR decline.

The relationship between the number of MetS components present and rapid eGFR decline is presented in Table 3. The risk of rapid eGFR decline increased as the number of MetS components increased, with ORs (95\% CIs) for one, two, three, four, and five components of 1.27 (0.68, 2.35), 1.94 (1.09, 3.47), 1.95 (1.07, 3.55), $3.47(1.92,6.29)$, and $3.19(1.64,6.22)$, respectively.

The results of subgroup analyses are displayed in Table 4. No significant heterogeneity was observed with regard to nearly all the parameters tested: sex, age $(<65$ or $\geq 65$ years), eGFR ( $<90$ or $\geq 90 \mathrm{~mL} / \mathrm{min} / 1.73 \mathrm{~m}^{2}$ ), current drinking (no or yes), or LDL-C $(<3.4$ or $\geq 3.4 \mathrm{mmol} / \mathrm{L})$. However, the OR for rapid eGFR decline was significantly higher in participants who were current smokers $(P$-interaction=0.030).

\section{Discussion}

The present study has shown that the presence of the MetS, individual components of the MetS, and the number of components present are independently associated with the risk of rapid eGFR decline in members of a Chinese community with eGFR $\geq 60 \mathrm{~mL} / \mathrm{min} / 1.73 \mathrm{~m}^{2}$. This finding is consistent with that of a previous prospective study performed in an Asian population. ${ }^{9}$

The MetS was found to be an important risk factor for deteriorating renal function. Recent studies have shown that the MetS plays an important role in the progression of CKD. ${ }^{11}$ Huh et al have reported that individuals with the MetS has a higher risk of CKD after adjustment for potential confounders (OR: 1.38, 95\% CI: 1.16-1.64). They also found that the MetS is positively associated with the risk of a rapid decline in eGFR (OR: 1.20, 95\% CI: 1.04-1.39). ${ }^{12}$ In addition, the Jackson Heart study showed a positive relationship between the severity of the MetS and a rapid eGFR decline in African-American women. ${ }^{26}$ Furthermore, a recent study derived from the Aichi Cohort Study of Prognosis in Patients Newly Initiated into Dialysis revealed that the rapidity of the decline in kidney function, which is similar to rapid eGFR decline, is positively correlated with all-cause mortality and CVD-related mortality. ${ }^{27}$ However, Cheng et al have reported a negative association between rapid eGFR decline and the MetS, with an OR of 1.04 (95\% CI: 0.80- 
Table 2 The Relationships Of MetS And Its Components With Rapid eGFR Decline

\begin{tabular}{|c|c|c|c|c|c|c|c|}
\hline \multirow[t]{2}{*}{ Variables } & \multirow{2}{*}{$\begin{array}{l}\text { Rapid eGFR } \\
\text { Decline, n(\%) }\end{array}$} & \multicolumn{2}{|l|}{ Model I } & \multicolumn{2}{|l|}{ Model II } & \multicolumn{2}{|l|}{ Model III } \\
\hline & & $\begin{array}{l}\text { OR } \\
(95 \% \mathrm{CI})\end{array}$ & P-value & $\begin{array}{l}\text { OR } \\
(95 \% \mathrm{CI})\end{array}$ & P-value & $\begin{array}{l}\text { OR } \\
(95 \% \mathrm{Cl})\end{array}$ & P-value \\
\hline $\begin{array}{r}\text { MetS } \\
\text { No } \\
\text { Yes }\end{array}$ & $\begin{array}{l}104(5.73) \\
121(9.37)\end{array}$ & $\begin{array}{l}\text { I } \\
1.69(1.28,2.23)\end{array}$ & $<0.001$ & $\begin{array}{l}\text { I } \\
1.78(1.34,2.35)\end{array}$ & $<0.001$ & & \\
\hline $\begin{array}{l}\text { MetS components } \\
\text { Waist circumference } \\
\quad<90 / 80 \mathrm{~cm}(\mathrm{M} / \mathrm{F}) \\
\geq 90 / 80 \mathrm{~cm}(\mathrm{M} / \mathrm{F})\end{array}$ & $\begin{array}{l}99(6.24) \\
126(8.38)\end{array}$ & $\mathrm{I} .30(0.98,1.72)$ & 0.07 & $\begin{array}{l}1 \\
1.38(1.04,1.83)\end{array}$ & 0.027 & I. $13(0.84,1.53)$ & 0.415 \\
\hline $\begin{array}{l}\text { Triglycerides } \\
<1.7 \mathrm{mmol} / \mathrm{L} \\
\geq 1.7 \mathrm{mmol} / \mathrm{L} \\
\text { or on treatment }\end{array}$ & $\begin{array}{l}\text { I33 (6.64) } \\
91(8.40)\end{array}$ & $\begin{array}{l}\text { I } \\
\text { I.3। }(0.99,1.73)\end{array}$ & 0.057 & $\begin{array}{l}\text { I } \\
1.40(1.05,1.86)\end{array}$ & 0.022 & $\begin{array}{l}\text { I } \\
\text { I. } 18(0.84,1.66)\end{array}$ & 0.328 \\
\hline $\begin{array}{l}\text { HDL cholesterol } \\
\geq 1.0 / 1.3 \mathrm{mmol} / \mathrm{L}(\mathrm{M} / \mathrm{F}) \\
<1.0 / 1.3 \mathrm{mmol} / \mathrm{L}(\mathrm{M} / \mathrm{F}) \\
\text { or on treatment }\end{array}$ & $\begin{array}{l}142(6.55) \\
79(8.66)\end{array}$ & $\begin{array}{l}\text { I } \\
1.30(0.97,1.73)\end{array}$ & 0.080 & $\begin{array}{l}\text { I } \\
1.26(0.94,1.69)\end{array}$ & 0.117 & $\begin{array}{l}\text { I } \\
0.97(0.68,1.38)\end{array}$ & 0.866 \\
\hline $\begin{array}{l}\text { Blood pressure } \\
<130 / 85 \mathrm{~mm} \mathrm{Hg} \\
\geq 130 / 85 \mathrm{~mm} \mathrm{Hg} \\
\text { or on medication }\end{array}$ & $\begin{array}{l}60(4.89) \\
163(8.71)\end{array}$ & $\begin{array}{l}\text { I } \\
\text { I.97 (I.44, 2.7I) }\end{array}$ & $<0.001$ & $\begin{array}{l}\text { I } \\
2.05(1.49,2.82)\end{array}$ & $<0.001$ & $\begin{array}{l}\text { I } \\
\text { I.83 (I.32, 2.55) }\end{array}$ & $<0.001$ \\
\hline $\begin{array}{l}\text { Fasting plasma glucose } \\
\qquad 5.6 \mathrm{mmol} / \mathrm{L} \\
\geq 5.6 \mathrm{mmol} / \mathrm{L} \\
\text { or known diabetic }\end{array}$ & $\begin{array}{l}76(5.12) \\
148(9.33)\end{array}$ & $\begin{array}{l}\text { I } \\
2.06(1.53,2.76)\end{array}$ & $<0.001$ & $2.12(1.57,2.85)$ & $<0.001$ & $\begin{array}{l}\text { I } \\
\text { I.82 (I.34, 2.47) }\end{array}$ & $<0.001$ \\
\hline
\end{tabular}

Notes: Model I: adjusted for age, sex, and eGFR. Model II: adjusted for age, sex, eGFR, smoking, drinking, and LDL-C. Model III: the five MetS components were included together, and adjusted for age, sex, eGFR, smoking, drinking, and LDL-C.

Abbreviations: OR, odds ratio; $\mathrm{Cl}$, confidence interval; MetS, metabolic syndrome; HDL-C, high-density lipoprotein-cholesterol; LDL-C, low-density lipoproteincholesterol.

Table 3 The Relationships Between The Number Of MetS Components And Rapid eGFR Decline

\begin{tabular}{|c|c|c|c|c|c|c|c|}
\hline \multirow[t]{2}{*}{ Variables } & \multirow{2}{*}{$\begin{array}{l}\text { Rapid eGFR } \\
\text { Decline, n(\%) }\end{array}$} & \multicolumn{2}{|l|}{ Crude Model } & \multicolumn{2}{|l|}{ Model I } & \multicolumn{2}{|l|}{ Model II } \\
\hline & & OR $(95 \% \mathrm{Cl})$ & $P$-value & OR $(95 \% \mathrm{Cl})$ & $P$-value & OR $(95 \% \mathrm{Cl})$ & $P$-value \\
\hline \multicolumn{8}{|l|}{ MetS components } \\
\hline 0 & 17 (4.49) & I & & I & & I & \\
\hline I & $32(4.83)$ & $1.08(0.59,1.98)$ & 0.798 & I.I $(0.62,2.09)$ & 0.671 & $1.27(0.68,2.35)$ & 0.455 \\
\hline 2 & $55(7.10)$ & $1.63(0.93,2.84)$ & 0.088 & $1.74(0.99,3.07)$ & 0.053 & $1.94(1.09,3.47)$ & 0.025 \\
\hline 3 & $44(6.93)$ & $1.59(0.89,2.82)$ & 0.116 & $1.68(0.94,3.00)$ & 0.081 & $1.95(1.07,3.55)$ & 0.029 \\
\hline 4 & $52(11.63)$ & $2.80(1.59,4.94)$ & 0.001 & $2.99(1.68,5.32)$ & $<0.001$ & $3.47(1.92,6.29)$ & $<0.001$ \\
\hline 5 & $25(11.90)$ & $2.88(1.52,5.46)$ & 0.001 & $2.94(1.53,5.66)$ & 0.001 & $3.19(1.64,6.22)$ & $<0.001$ \\
\hline$P$ for trend & & \multicolumn{2}{|l|}{$<0.001$} & \multicolumn{2}{|l|}{$<0.001$} & \multicolumn{2}{|l|}{$<0.001$} \\
\hline
\end{tabular}

Notes: Model I: adjusted for age, sex, and eGFR. Model II: adjusted for age, sex, eGFR, smoking, drinking, and LDL-C.

Abbreviations: $\mathrm{OR}$, odds ratio; $\mathrm{Cl}$, confidence interval; MetS, metabolic syndrome.

1.36) after adjustment for covariates. ${ }^{23}$ Therefore, therapy aimed at reducing the rate of renal deterioration may represent an alternative approach to reducing the risks of all-cause and CVD-related mortality. Although the relationship between the MetS and CKD has been extensively studied, few prospective studies have been conducted in 
Table 4 Effect Of The Metabolic Syndrome On The Risk Of Rapid eGFR Decline By Subgroups

\begin{tabular}{|c|c|c|c|c|}
\hline Characteristic & Rapid eGFR Decline, n(\%) & OR $(95 \% \mathrm{Cl})$ & P-value & P-Interaction \\
\hline Age (years) & & & & 0.432 \\
\hline$<65$ & $185(6.96)$ & $1.89(1.39,2.57)$ & $<0.001$ & \\
\hline$\geq 65$ & $40(9.07)$ & $1.40(0.70,2.82)$ & 0.345 & \\
\hline Sex & & & & 0.799 \\
\hline Male & $61(5.62)$ & $1.88(1.11,3.16)$ & 0.018 & \\
\hline Female & $164(8.14)$ & $1.70(1.21,2.39)$ & 0.002 & \\
\hline eGFR, $\mathrm{mL} / \mathrm{min}$ per $1.73 \mathrm{~m}^{2}$ & & & & 0.362 \\
\hline$\geq 90$ & $193(7.06)$ & $1.92(I .42,2.61)$ & $<0.001$ & \\
\hline$<90$ & $32(8.77)$ & $1.00(0.46,2.15)$ & 0.999 & \\
\hline Current smoking & & & & 0.030 \\
\hline No & $195(7.78)$ & $1.57(1.16,2.13)$ & 0.004 & \\
\hline Yes & $30(5.06)$ & $3.78(1.68,8.49)$ & 0.001 & \\
\hline Current drinking & & & & 0.148 \\
\hline No & $213(8.99)$ & $1.94(1.42,2.65)$ & $<0.001$ & \\
\hline Yes & $12(1.65)$ & I.II $(0.56,2.18)$ & 0.764 & \\
\hline LDL-C, $\mathrm{mmol} / \mathrm{L}$ & & & & 0.932 \\
\hline$<3.4$ & |4| (7.68) & $1.82(1.28,2.61)$ & 0.001 & \\
\hline$\geq 3.4$ & $82(6.49)$ & $1.63(1.02,2.59)$ & 0.040 & \\
\hline
\end{tabular}

Notes: The model was adjusted for age, sex, eGFR, smoking, drinking, and LDL-C.

Abbreviations: OR, odds ratio; Cl, confidence interval; HDL, high-density lipoprotein; LDL-C, low-density lipoprotein-cholesterol; BMI, body mass index.

patients from mainland China, and rapidity of the decline in kidney function has not typically been assessed. To our knowledge, this is the first community-based prospective study to determine the relationship between the MetS and a rapid decline in eGFR in China.

In the present study, nearly all the individual components of the MetS were found to be positively associated with the risk of rapid eGFR decline, with the exception of HDL-C. The results of previous similar studies conducted in different populations have been contradictory. For instance, the Arkhangelsk study showed that hypertension was a key contributory factor to cardiovascular disease in a Russian population. ${ }^{28}$ In contrast, another recent study showed that only high fasting glucose (OR: 1.52, 95\% CI: 1.12-2.05) was significantly associated with a reduction in renal function, after adjustment for age, sex, current smoking, current drinking, uric acid concentration, and all the other components of the MetS. ${ }^{9}$ Furthermore, Ding et al found that a high concentration of circulating triglyceride was strongly associated with CKD (hazard ratio: 1.14, 95\% CI: $1.08-1.21$ ). ${ }^{29}$ Other studies have shown that a reduction in HDL-C is associated with a significantly higher risk of $\mathrm{CKD} .^{33}$

High FBG and BP are shown to be the two components of the MetS with the largest ORs for a rapid decline in
eGFR: $2.12(1.57,2.85)$ and $2.05(1.49,2.82)$, respectively. These results indicate that high FBG and BP are more reliable predictors of rapid eGFR decline than the MetS itself. The possible explanation may be that our participants were part of a community-based population mainly accompanied with diabetes and/or hypertension, both of which are the main causes of kidney disease and may be associated with a higher risk of rapid eGFR decline. The Jackson Heart Study of 4933 AfricanAmericans also showed that high BP, FBG, triglycerides, and abdominal obesity are significantly associated with the risk of CKD. However, the risks of CKD associated with high FBG and BP were higher than those associated with the other components of the MetS (OR [95\% CI]: 4.41 [2.99-6.49] and 1.99 [1.60-2.47], respectively). ${ }^{30}$

A graded relationship has previously been identified between the risk of CKD and the number of components of the MetS present. A cross-sectional study of older adult Japanese community-dwelling women showed that the number of MetS components is associated with the prevalence of $\mathrm{CKD}$ in non-obese subjects. ${ }^{31}$ Moreover, Okada et al found that both early- and late-stage kidney pathology increased with the number of MetS components present and that this association was statistically significant in both 
normal-weight and overweight individuals. ${ }^{32}$ Therefore, it seems that a combination of MetS components plays an active role in the deterioration of kidney function.

The present study has also revealed a positive relationship between the number of MetS components and rapid eGFR decline, consistent with the findings of previous studies. ${ }^{20}$ Participants with five components of the MetS had an OR $(95 \% \mathrm{CI})$ of $3.19(1.64,6.22)$ in the fully adjusted model, which represented a similar level of risk to that identified in another study. ${ }^{9}$ We can infer that a combination of MetS components, regardless of their identity, might increase the risk of kidney dysfunction. Thus, in clinical practice, the presence of any MetS component should provoke an appropriate intervention, even if the diagnostic criteria for the MetS are not met.

The subgroup analyses identified an interaction between the MetS and current smoking with regard to the risk of rapid eGFR decline because the OR for rapid eGFR decline associated with the MetS was significantly higher in participants who were current smokers $(P$-interaction=0.030). There could be two explanations for this finding. First, cell culture studies have repeatedly shown that nicotine-induced mesangial cell proliferation impairs their function, and kidney biopsies of active smokers demonstrate histopathologic changes, ${ }^{13,14}$ and second, smoking promotes local oxidative stress. ${ }^{15,16}$

Several limitations of the present study should be noted. First, the participants were only followed for a median of 2.34 years, which may have limited the magnitude of the effect observed; therefore, a study containing a larger number of participants with this problem may be required to validate the identified relationship. Second, few covariates were adjusted for other than the components of the MetS; therefore, it was not possible to determine whether the presence of the MetS, independent of its single components, was associated with the risk of rapid eGFR decline. Finally, our study contained only Chinese participants, and therefore, the results may not be generalizable to other populations.

\section{Conclusions}

This study has shown that the MetS and its individual components are significantly associated with the risk of rapid eGFR decline in a population with normal renal function. In addition, we have shown that the risk of rapid eGFR decline increases with the number of MetS components present. High FBG and BP were the two most significant risk factors.

\section{Abbreviations}

MetS, metabolic syndrome; eGFR, estimated glomerular filtration rate; CKD, chronic kidney disease; HDL-C, high-density lipoprotein-cholesterol; BP, blood pressure; BMI, body mass index; LDL-C, low-density lipoprotein-cholesterol.

\section{Ethics Approval And Informed Consent}

The participants gave their written informed consent. The study protocol was approved by the Ethics Committees of both Peking University and Peking University First Hospital (approval numbers: IRB00001052-11086; date: 2013-12-31) and the study was conducted in accordance with the principles of the Declaration of Helsinki.

\section{Data Availability}

The datasets used and/or analyzed during the current study are available from the corresponding author on reasonable request.

\section{Acknowledgments}

We thank all study team members for their participation. We are also grateful for the organization by site managers Dr. Shuyu Wang and Dr. Liguang Dong. We thank Mark Cleasby, PhD, from Liwen Bianji, Edanz Group China, for editing the English text of a draft of this manuscript.

\section{Author Contributions}

Conception and design: YZ, FF, JL, YH, JJ, YJ, DH, PS, and ZW. Acquisition of data: FF, JJ, YJ, DH, PS, and ZW. Analysis and interpretation of data: FF, JJ, PS, and ZW.

Drafting of the article: ZW. Revision of the article: YZ, FF, JL, YH, JJ, YJ, DH, PS, and ZW. The final manuscript has been reviewed and approved by all authors. All authors agree to be accountable for all aspects of the work in ensuring that questions related to the accuracy or integrity of any part of the work are appropriately investigated and resolved.

\section{Funding}

This study was supported by grants from the University of Michigan - Peking University Health Science Centre (UM-PUHSC) Joint Institute for Translational and Clinical Research (grant numbers BMU20110177 and BMU20160530) and Projects of the National Natural Science Foundation of China (grant number 81703288).

\section{Disclosure}

The authors report no conflicts of interest in this work. 


\section{References}

1. Aguilar M, Bhuket T, Torres S, Liu B, Wong RJ. Prevalence of the metabolic syndrome in the United States, 2003-2012. JAMA. 2015;313(19):1973-1974. doi:10.1001/jama.2015.4260

2. Li R, Li W, Lun Z, et al. Prevalence of metabolic syndrome in Mainland China: a meta-analysis of published studies. BMC Public Health. 2016;16:296. doi:10.1186/s12889-016-2870-y

3. Eckel RH, Grundy SM, Zimmet PZ. The metabolic syndrome. Lancet. 2005;365(9468):1415-1428. doi:10.1016/S0140-6736(05)66378-7

4. Wilson PW, D'Agostino RB, Parise H, Sullivan L, Meigs JB. Metabolic syndrome as a precursor of cardiovascular disease and type 2 diabetes mellitus. Circulation. 2005;112(20):3066-3072. doi:10.1161/CIRCULATIONAHA.105.539528

5. Wu SH, Liu Z, Ho SC. Metabolic syndrome and all-cause mortality: a meta-analysis of prospective cohort studies. Eur Epidemiol. 2010;25(6):375-384. doi:10.1007/s10654-010-9459-z

6. Zhang L, Wang F, Wang L, et al. Prevalence of chronic kidney disease in China: a cross-sectional survey. Lancet. 2012;379 (9818):815-822. doi:10.1016/S0140-6736(12)60033-6

7. Chen J, Muntner P, Hamm LL, et al. The metabolic syndrome and chronic kidney disease in U.S. adults. Ann. Intern Med. 2004;140 (3):167-174.

8. Kawada T. Association between metabolic syndrome and chronic kidney disease. Clin Chim Acta. 2018;478:44. doi:10.1016/j. cca.2017.12.020

9. Chen J, Kong XL, Jia XY, et al. Association between metabolic syndrome and chronic kidney disease in a Chinese urban population. Clin Chim Acta. 2017;470:103-108. doi:10.1016/j.cca.2017.05.012

10. Li Y, Chen Y, Liu X, et al. Metabolic syndrome and chronic kidney disease in a Southern Chinese population. Nephrology (Carlton). 2014;19(6):325-331. doi:10.1111/nep.12219

11. Saito T, Mochizuki T, Uchida K, Tsuchiya K, Nitta K. Metabolic syndrome and risk of progression of chronic kidney disease: a singlecenter cohort study in Japan. Heart Vessels. 2013;28(3):323-329. doi:10.1007/s00380-012-0254-5

12. Huh JH, Yadav D, Kim JS, et al. An association of metabolic syndrome and chronic kidney disease from a 10-year prospective cohort study. Metabolism. 2017;67:54-61. doi:10.1016/j. metabol.2016.11.003

13. Dasgupta P, Chellappan SP. Nicotine-mediated cell proliferation and angiogenesis: new twists to an old story. Cell Cycle. 2006;5 (20):2324-2328. doi:10.4161/cc.5.20.3366

14. Jaimes EA, Tian RX, Raij L. Nicotine: the link between cigarette smoking and the progression of renal injury? Am J Physiol Heart Circ Physiol. 2007;292(1):H76-H82. doi:10.1152/ajpheart.00693.2006

15. Odoni G, Ogata H, Viedt C, Amann K, Ritz E, Orth SR. Cigarette smoke condensate aggravates renal injury in the renal ablation model. Kidney Int. 2002;61(6):2090-2098. doi:10.1046/j.1523-1755.2002.00382.x

16. Ozbek E. Induction of oxidative stress in kidney (published online ahead of print April 17, 2012). Int J Nephrol. doi:10.1155/2012/465897

17. Thomas G, Sehgal AR, Kashyap SR, Srinivas TR, Kirwan JP, Navaneethan SD. Metabolic syndrome and kidney disease: a systematic review and meta-analysis. Clin J Am Soc Nephrol. 2011;6 (10):2364-2373. doi:10.2215/CJN.02180311

18. Li Y, Xie D, Qin X, et al. Metabolic syndrome, but not insulin resistance, is associated with an increased risk of renal function decline. Clin Nutr. 2015;34(2):269-275. doi:10.1016/j.clnu.2014.04.002

19. Navaneethan SD, Schold JD, Kirwan JP, et al. Metabolic syndrome, ESRD, and death in CKD. Clin J Am Soc Nephrol. 2013;8(6):945952. doi:10.2215/CJN.09870912
20. Zomorrodian D, Khajavi-Rad A, Avan A, et al. Metabolic syndrome components as markers to prognosticate the risk of developing chronic kidney disease: evidence-based study with 6492 individuals. J Epidemiol Commun H. 2015;69(6):594-598. doi:10.1136/jech-2014-205160

21. Fan F, Jia J, Li J, et al. White blood cell count predicts the odds of kidney function decline in a Chinese community-based population. BMC Nephrol. 2017;18(1):190. doi:10.1186/s12882-017-0669-4

22. Levey AS, Stevens LA, Schmid CH, et al. CKD-EPI (Chronic Kidney Disease Epidemiology Collaboration) a new equation to estimate glomerular filtration rate. Ann Intern Med. 2009;150:604612. doi:10.7326/0003-4819-150-9-200905050-00006

23. Cheng HT, Huang JW, Chiang CK, et al. Metabolic syndrome and insulin resistance as risk factors for development of chronic kidney disease and rapid decline in renal function in elderly. $J$ Clin Endocrinol Metab. 2012;97(4):1268-1276. doi:10.1210/jc.2011-2658

24. Ford ES. Risks for all-cause mortality, cardiovascular disease, and diabetes associated with the metabolic syndrome: a summary of the evidence. Diabetes Care. 2005;28:1769-1778. doi:10.2337/ diacare.28.7.1769

25. Alberti KG, Eckel RH, Grundy SM, et al. International Diabetes Federation Task Force on Epidemiology and Prevention, National Heart, Lung, and Blood Institute, American Heart Association, World Heart Federation, International Atherosclerosis Society, International Association for the Study of Obesity. Harmonizing the metabolic syndrome: a joint interim statement of the International Diabetes Federation Task Force on Epidemiology and Prevention; National Heart, Lung, and Blood Institute; American Heart Association; World Heart Federation; International Atherosclerosis Society; and International Association for the Study of Obesity. Circulation. 2009;120:1640e5.

26. DeBoer MD, Filipp SL, Musani SK, Sims M, Okusa MD, Gurka M. Metabolic syndrome severity and risk of CKD and worsened GFR: the Jackson Heart Study. Kidney Blood Press Res. 2018;43(2):555567. doi: $10.1159 / 000488829$

27. Inaguma D, Murata M, Tanaka A, Shinjo H. Relationship between mortality and speed of eGFR decline in the 3 months prior to dialysis initiation. Clin Exp Nephrol. 2017;21(1):159-168. doi:10.1007/ s10157-016-1262-z

28. Sidorenkov O, Nilssen O, Brenn T, Martiushov S, Arkhipovsky VL, Grjibovski AM. Prevalence of the metabolic syndrome and its components in Northwest Russia: the Arkhangelsk study. BMC Public Health. 2010;10:23. doi:10.1186/1471-2458-10-23

29. Ding C, Yang Z, Wang S, Sun F, Zhan S. The associations of metabolic syndrome with incident hypertension, type 2 diabetes mellitus and chronic kidney disease: a cohort study. Endocrine. 2018;60(2):282-291. doi:10.1007/s12020-018-1552-1

30. Mendy VL, Azevedo MJ, Sarpong DF, et al. The association between individual and combined components of metabolic syndrome and chronic kidney disease among African Americans: the Jackson Heart Study. PLoS One. 2014;9(7):e101610. doi:10.1371/journal.pone.0101610

31. Kurata M, Tsuboi A, Takeuchi M, Fukuo K, Kazumi T. Association of metabolic syndrome with chronic kidney disease in elderly Japanese women: comparison by estimation of glomerular filtration rate from creatinine, cystatin C, and both. Metab Syndr Relat D. 2016;14(1):40-45. doi:10.1089/met.2015.0085

32. Okada R, Yasuda Y, Tsushita K, Wakai K, Hamajima N, Matsuo S. The number of metabolic syndrome components is a good risk indicator for both early- and late-stage kidney damage. Nutr Metab Cardiovas. 2014;24(3):277-285. doi:10.1016/j.numecd.2013.08.004

33. Kurella M, Lo JC, Chertow GM. Metabolic syndrome and the risk for chronic kidney disease among nondiabetic adults. Am Soc Nephrol. 2005;16:2134-2140. doi:10.1681/ASN.2005010106 


\section{Publish your work in this journal}

Diabetes, Metabolic Syndrome and Obesity: Targets and Therapy is an international, peer-reviewed open-access journal committed to the rapid publication of the latest laboratory and clinical findings in the fields of diabetes, metabolic syndrome and obesity research. Original research, review, case reports, hypothesis formation, expert opinion and commentaries are all considered for publication. The manuscript management system is completely online and includes a very quick and fair peer-review system, which is all easy to use. Visit http://www.dovepress.com/testimonials.php to read real quotes from published authors.

Submit your manuscript here: https://www.dovepress.com/diabetes-metabolic-syndrome-and-obesity-targets-and-therapy-journal 